\title{
A Pore Water Model of Dynamic Compaction
}

\author{
Yao Xu ${ }^{a, *}$, Ping Hu ${ }^{b}$ \\ School of Civil Engineering and Architecture, University of Jinan, Jinan 250022, China \\ abluewind7979@163.com, b583493@qq.com
}

Keywords: Dynamic Compaction, Degree of consolidation, Pore Water Pressure, Permeability.

\begin{abstract}
The pore pressure test is designed in a dynamic compaction engineering, and the data on dissipation and increase of the pore pressure are gotten. The function of pore water pressure is fitted by regression analysis. The design parameters of time interval between two dynamic compaction can be determined by the function.
\end{abstract}

\section{Introduction}

Dynamic compaction is also called dynamic consolidation that the 10 40t hammer is raised highly, then let it free fall, and the ground is buffeted and vibrated. So the bearing capacity of the foundation is increased and its compressibility is reduced. The foundation treatment of dynamic compaction has many advantages such as good treatment effect, Simple process, low cost and so on, hence it gets extensive engineering applications, but in theory it needs to be perfected.

In engineering dynamic compaction of many times is applied to treat foundation in order to get good effect. The excess pore water pressure emerges in the ground of high underground water level, so the time interval between compaction of many times is necessary to make the excess pore water pressure dissipate. If there is no enough time interval, the excess pore water pressure in ground is still high. If the compaction is carried out rashly at this time, the ground will be bad.

So it is necessary to build the practical model of excess pore water pressure, which is used to determine the time interval between compaction of many times. Therefore the data on dissipation and increase of the pore pressure are gotten, the function of pore water pressure is fitted by regression analysis and the design parameters of time interval between two dynamic compaction can be determined by the function.

\section{Engineering geological conditions}

The test site with the high underground water level is located in the Yellow River overflow area. The ground soil is divided into four layers, which is (1)-1 plain fill, (1) silt soil, (1)-2 silty clay, (2) silt sand, (2)-2 silt soil, (3) silty clay and (4) silt soil. The bearing capacity of each layer is about 100kpa. The layers of (1) silt soil, (1)-2 silty clay, (2) silt, and (3) silty clay have high compressibility. And the layers of (2)-2 silt soil and (4) silt soil have medium compressibility.

\section{Test design}

\subsection{Testing program design.}

The test site is divided into two parts, east part and west part. The east part includes four regions and the west part is divided into two regions. The area of each region is $900 \mathrm{~m}^{2}$ and the interval of each part is $5 \mathrm{~m}$. The dynamic consolidation construction parameters are shown in Tab. 1 .

\subsection{Embedded pore-water pressure instruments.}

Four pore-water pressure instruments are embedded from $\mathrm{T} 1$ to $\mathrm{T} 4$ site at the depth of $5 \mathrm{~m}, 7 \mathrm{~m}$, $10 \mathrm{~m}$ and $13 \mathrm{~m}$. They are located in the silt, silty clay, silt and silty sand respectively. In addition five pore-water pressure instruments are embedded in the T5 and T6 site at the depth of $4.5 \mathrm{~m}, 6 \mathrm{~m}, 7.5 \mathrm{~m}$, $9.5 \mathrm{~m}$ and $13 \mathrm{~m}$. They are located in the silt soil, silt soil, silty clay, silty clay and silty sand 
respectively. The excess pore-water pressure is measured during compaction. Immediately after compaction the excess pore water pressure is measured at the time of 2 minutes, 5 minutes, 10 minutes, 30 minutes, 4 hours, 8 hours, 24 hours, 48 hours and 72 hours respectively.

Tab. 1 Dynamic consolidation construction parameters of test site

\begin{tabular}{|c|c|c|c|c|c|c|c|c|}
\hline \multirow{2}{*}{ Site number } & \multicolumn{2}{|c|}{ Compaction spot layout $[\mathrm{m} \times \mathrm{m}]$} & \multicolumn{3}{|c|}{ Tamping number of each compaction spot $[\mathrm{n}]$} & \multicolumn{3}{|c|}{$\begin{array}{c}\text { Compaction energy } \\
{[\mathrm{kN} \cdot \mathrm{m}]} \\
\end{array}$} \\
\hline & $\begin{array}{c}\text { First } \\
\text { compaction }\end{array}$ & $\begin{array}{c}\text { Second } \\
\text { compaction }\end{array}$ & $\begin{array}{c}\text { First } \\
\text { compaction }\end{array}$ & $\begin{array}{c}\text { Second } \\
\text { compaction }\end{array}$ & $\begin{array}{c}\text { Full } \\
\text { compaction }\end{array}$ & $\begin{array}{c}\text { First } \\
\text { compaction }\end{array}$ & $\begin{array}{c}\text { Second } \\
\text { compaction }\end{array}$ & $\begin{array}{c}\text { Full } \\
\text { compaction }\end{array}$ \\
\hline $\mathrm{T} 1$ & $6.0 \times 7.5$ & $6.0 \times 7.5$ & $8 \sim 10$ & $7 \sim 8$ & 2 & 2000 & 2000 & 800 \\
\hline $\mathrm{T} 2$ & $6.0 \times 5.2$ & $6.0 \times 5.2$ & $8 \sim 10$ & $7 \sim 8$ & 2 & 3000 & 2000 & 800 \\
\hline $\mathrm{T} 3$ & $3.5 \times 7.0$ & $3.5 \times 7.0$ & $8 \sim 10$ & $7 \sim 8$ & 2 & 2000 & 2000 & 800 \\
\hline $\mathrm{T} 4$ & $7.0 \times 7.0$ & $7.0 \times 7.0$ & $8 \sim 10$ & $7 \sim 8$ & 2 & 2000 & 2000 & 800 \\
\hline T5 & $5.0 \times 3.5$ & $5.0 \times 3.5$ & $8 \sim 10$ & $7 \sim 8$ & 2 & 3000 & 2000 & 800 \\
\hline T6 & $8.0 \times 8.0$ & $8.0 \times 8.0$ & $8 \sim 10$ & $7 \sim 8$ & 2 & 2000 & 2000 & 800 \\
\hline
\end{tabular}

\section{Result of test}

\subsection{Increase law of excess pore water pressure during compaction.}

The curves of excess pore water pressure increase are shown from Fig. 1 to Fig. 4. The following laws can be gotten.
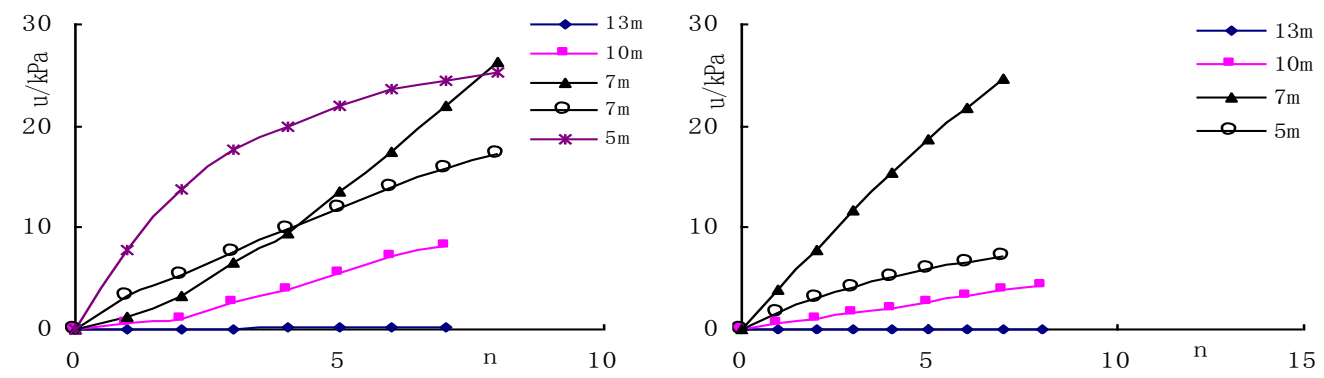

Fig1 Excess pore water pressure during 2nd compaction in T1 site

Fig2 Excess pore water pressure during 3rd compaction in T4 site
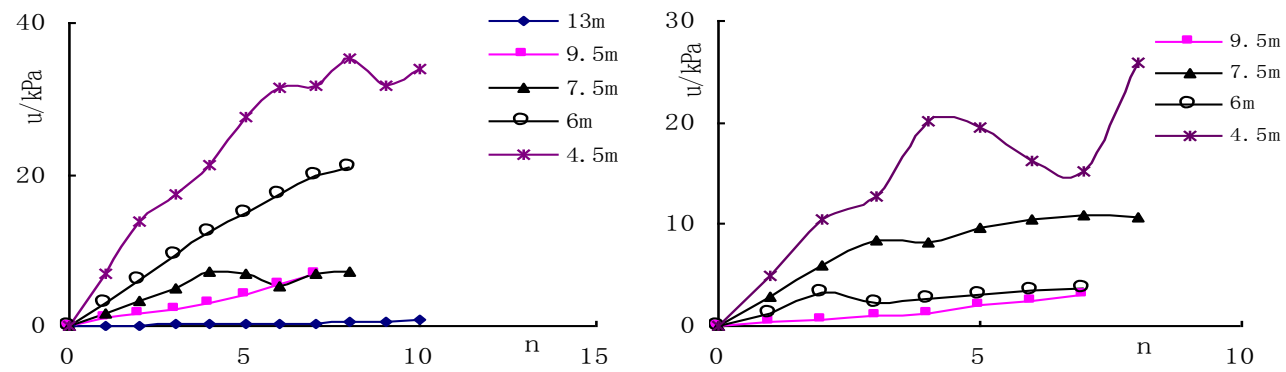

Fig3 Excess pore water pressure during 1 st compaction in T5 site

Fig4 Excess pore water pressure during 2nd compaction in T5 site

Firstly, the excess pore water pressure at the superficial layer increases obviously and reaches saturation gradually with the tamping number under the compaction energy of $2000 \sim 3000 \mathrm{kN} \cdot \mathrm{m}$. However that at the depth of $10 \mathrm{~m}$ and $13 \mathrm{~m}$ changes little. So the maximum impact depth of compaction energy of $2000 \sim 3000 \mathrm{kN} \cdot \mathrm{m}$ is 13 meters.

Secondly, in the east part, from $\mathrm{T} 1$ to $\mathrm{T} 4$, the excess pore water pressure at the depth of $5 \mathrm{~m}$ reaches saturation when the tamping number is 7 9. That at the depth of $7 \mathrm{~m}$ reaches saturation when the tamping number is $10 \sim 12$.

Thirdly, in the west part, from T1 to T2, the excess pore water pressure at the depth of $4.5 \mathrm{~m}$ reaches saturation when the tamping number is 5 7. That at the depth of $6 \mathrm{~m}$ reaches saturation when the tamping number is 7 8. That at the depth of $7.5 \mathrm{~m}$ reaches saturation under the 7 8 tamping numbers. 


\subsection{Dissipation law of excess pore water pressure.}

The curves of excess pore water pressure dissipation are shown from Fig. 5 to Fig. 6. The following laws can be gotten.

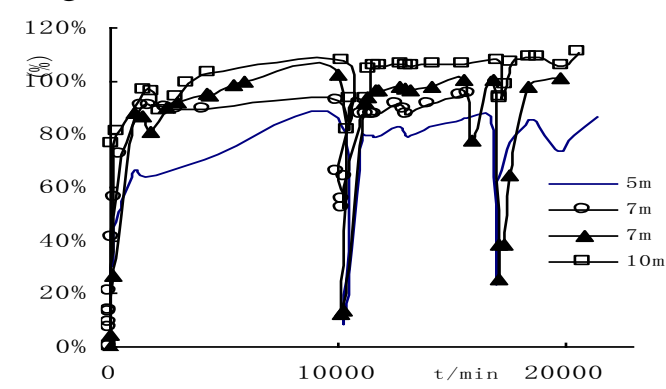

Fig5 Curves of consolidation degree of pore water pressure in $\mathrm{T} 1$ site

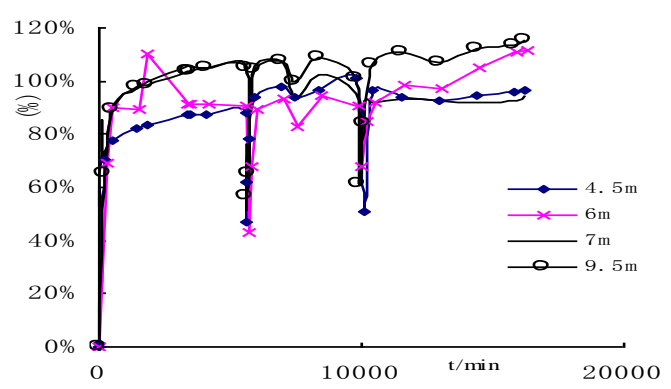

Fig6 Curves of consolidation degree of pore water pressure in T6 site

Firstly, more than $60 \%$ excess pore water pressure dissipates one day later after compaction in the east part. Secondly, $70 \%$ excess pore water pressure dissipates ten hours later after compaction in the west part, and $85 \%$ excess pore water pressure dissipates one day later after compaction.

\section{Pore water model of dynamic compaction}

\subsection{Influence factors of excess pore water pressure.}

The influence factors include burial depth, single -point total ramming energy, tamping times, cumulative mean ramming energy, and permeability coefficient.

First, the peak of pore water pressure is different from burial depth. So take depth as a factor affecting the peak of pore water pressure, and the order of magnitude is taken twice.

The single-point total ramming energy is second factor, which is the product of single-point ramming energy and single-point tamping number. For example the excess pore water pressure at the depth of $4.5 \mathrm{~m}$ reaches $33.88 \mathrm{kPa}$ corresponding to the single-point total ramming energy of $24000 \mathrm{kN} \cdot \mathrm{m}$ in the first compaction. And that reaches $10.86 \mathrm{kPa}$ corresponding to the single-point total ramming energy of $12000 \mathrm{kN} \cdot \mathrm{m}$ in the second compaction.

Third, the peak of pore water pressure is different from tamping times. For example the excess pore water pressure at the depth of $5 \mathrm{~m}$ in $\mathrm{T} 1$ site reaches $76.23 \mathrm{kPa}$ in the first compaction, $63.78 \mathrm{kPa}$ in the second compaction, and $60.34 \mathrm{kPa}$ in the third tamping. The excess pore water pressure at the depth of $4.5 \mathrm{~m}$ in $\mathrm{T} 6$ site reaches $60.43 \mathrm{kPa}$ in the first compaction, $32.19 \mathrm{kPa}$ in the second compaction, and $29.86 \mathrm{kPa}$ in the third tamping.

Fourth, the cumulative mean ramming energy takes into account the affect of tamping-energy spreading to the peak of pore water pressure. And because the tamping effect of every times compaction is influenced by each other, the cumulative mean ramming energy is consider as regression variables.

Fifth, the worse the permeability of the earth, the more the pressure of the ultra-static pore water that is produced by the compaction should not dissipate. On the contrary the stronger the permeability, the lower the peak of the ultra-static pore water pressure and the shorter the dissipation time. For example the geological conditions of this project are as follows. The permeability coefficient of sand is $1.8 \times 10^{-3} \mathrm{~cm} / \mathrm{s}$, that of silt soil is $3.6 \times 10^{-4} \mathrm{~cm} / \mathrm{s}$, and that of silty clay is $4.3 \times 10^{-5} \mathrm{~cm} / \mathrm{s}$. The $60 \%$ pressure of the ultra-static pore water dissipates one day later after compaction in the silty clay, more than $70 \%$ ultra-static pore water pressure dissipates one day later after compaction in the silty soil, more than $80 \%$ ultra-static pore water pressure dissipates one day later after compaction in the silty sand.

\subsection{Function of excess pore water pressure.}

The function of excess pore water pressure is the product of peak function, $u_{0}$, and dissipation function, $u_{t}$. The expression is as follows.

$$
u=u_{0} \cdot u_{t}=f(w, z, n, p, k) \cdot f(k, t)
$$


First, the peak function can be written as:

$\hat{u}_{0}=a_{0}+a_{1} z+a_{2} z^{2}+a_{3} w+a_{4} n+a_{5} p+a_{6} k$

The coefficient of peak function can be determined by multivariate linear regression analysis program, then:

$a_{0}=-145.31, a_{1}=68.37, a_{2}=-5.07 a_{3}=-11.19, a_{4}=0.000223, a_{5}=0.0033, a_{6}=-0.28$

So the eq.(2) can be written as:

$\hat{u}_{0}=-145.31+68.37 z-5.07 z^{2}-11.19 n+0.000223 w+0.0033 p-0.28 k$

Second, the dissipation function of excess pore water pressure can be written as:

$\hat{y}=e^{\left(a_{1}+a_{2} k\right) t+a_{0}}$

The expression is exponential nonlinear regression equation. Take the logarithm on both sides of the equation and it can be converted into a linear regression equation. Then

$\ln \hat{y}=a_{0}+a_{1} t+a_{2} k t$

The coefficient of dissipation function can be determined by multivariate linear regression analysis program, then:

$a_{0}=-0.426, a_{1}=-0.0004, a_{3}=-0.00001$

So the eq.(4) can be written as:

$\hat{y}=e^{-0.426+(-0.0004-0.0000 k) t}$

Third, the function of excess pore water pressure is the product of peak function, $u_{0}$, and dissipation function, $u_{t}$. The expression is as follows.

$\hat{u}=\left(-145.31+68.37 z-5.07 z^{2}-11.19 n+0.000223 w+0.0033 p-0.28 k\right) \times e^{-0.426+(-0.0004-0.0000 k) t}$

The function can be used to obtain that the water pore pressure in silt soil ground dissipates completely one day, which is consistent to the test data. So the function can be used to determine the time interval between compaction.

\section{Summary}

The ultra-static pore water pressure is measured by dynamic compaction, the function of pore water pressure of dynamic compaction is fitted by regression analysis. The model is valuable to estimate the design parameters of the compaction, the time intervals between each compaction.

\section{Acknowledgements}

Project: Study on Test and Constitutive Theory of Deformation Characteristics of Silty Sand Considering Rotation of Main Stress Axis

Nature: National Natural Science Foundation of China Youth Project

Project Number: 51409120

\section{References}

[1] Xiaonan Gong, Foundation Treatment, Beijing: building industry press, 1999.

[2] Sengyuan Tian, Test Design and Data Processing, Beijing: building industry press, 1988. 